\title{
Vorteilhafte Verträge und Konfliktvermeidung
}

Machen Sie sich klar, dass auch der beste Ingenieurvertrag eine spätere gerichtliche Auseinandersetzung nicht ausschließen kann. Wenn Sie nun auf den Gedanken kommen, man benötige daher für die Gestaltung und Verhandlung eines Ingenieurvertrags keinen Anwalt, liegen Sie falsch. Je früher der Anwalt eingeschaltet wird, desto eher kann er mögliche Konfliktherde von vornherein ausschalten. Dies bietet sich vor allem bei Großbau- oder gebäudetechnisch anspruchsvollen Projekten an. Denn in der Praxis sind vielfach Widersprüche, Lücken oder Unklarheiten des Vertrags zwischen Auftraggeber und Ingenieur Auslöser von langen und teuren Streitigkeiten.

Ja, Anwälte sind mitunter teuer. Das sollte Sie jedoch nicht von der betriebswirtschaftlichen Überlegung abhalten, ob die Investition in einen Anwalt nicht genauso wichtig sein kann, wie die Investition z. B. in einen neuen Rechner oder Plotter. Denn die praktische und vor allem gerichtliche Erfahrung zeigt, dass die frühzeitige Einholung von Rechtsrat in der Regel Fehler in einem so großen Umfang vermeidet, dass der Anwalt sein Geld wert ist. 